\title{
Plasma flow channels with ULF waves observed by Cluster and Double Star
}

\author{
M. Volwerk ${ }^{1,2}$, T. L. Zhang ${ }^{1}$, R. Nakamura ${ }^{1}$, A. Runov $^{1}$, W. Baumjohann ${ }^{1}$, K.-H. Glassmeier ${ }^{3}$, T. Takada ${ }^{1}$, \\ H. U. Eichelberger ${ }^{1}$, C. M. Carr ${ }^{4}$, A. Balogh ${ }^{4}$, B. Klecker ${ }^{2}$, and H. Rème \\ ${ }^{1}$ Space Research Institute, Austrian Academy of Sciences, A-8042 Graz, Austria \\ ${ }^{2}$ Max-Planck Institute for Extraterrestrial Physics, D-85741 Garching, Germany \\ ${ }^{3}$ TU Braunschweig, D-38106 Braunschweig, Germany \\ ${ }^{4}$ Imperial College, London, SW7 2AZ, UK \\ ${ }^{5}$ CESR/CNRS, F-31028 Toulouse, France
}

Received: 17 February 2005 - Revised: 19 April 2005 - Accepted: 23 May 2005 - Published: 8 November 2005

Part of Special Issue "Double Star - First Results"

\begin{abstract}
On 14 August 2004 a large-scale magnetic structure was observed by Double Star TC-1 in the southern lobe and by Cluster in the northern lobe of the magnetotail. The structure has the signature of a (localized) dipolarization, decreasing $B_{\mathrm{x}}$ accompanied by an increasing $B_{\mathrm{Z}}$ and a strong earthward flow. The propagation direction of this structure, however, seems to be more in the dawnward direction than earthward. The structure is accompanied by ULF waves with a period of $\sim 5 \mathrm{~min}$, which are simultaneously observed by the ground magnetometer station DIK, at the magnetic footpoints of the spacecraft. We interprete these waves as modes driven by the plasma flow and propagating in the flow channel.
\end{abstract}

Keywords. Magnetopheric physics (Magnetotail, MHD waves and instabilities, Plasma sheet)

\section{Introduction}

The Cluster mission was developed to obtain a threedimensional view of the Earth's magnetosphere at different scales (varying from $500 \mathrm{~km}$ separation in 2003 to $4000 \mathrm{~km}$ in 2002). In the study of the dynamics of the Earth's magnetotail, this mission has provided us with a detailed view of the processes taking place at radial distances of $\sim 19 R_{E}$. Processes that have been studied experimentally in the magnetotail, like compressional waves (Chen and Kivelson, 1991; Bauer et al., 1995a,b) and bursty bulk flows (Angelopoulos et al., 1992, 1994), are subject to a multipoint analysis now, which has been shown to be very fruitful (Zhou et al., 1997). Similarly, the theoretical and numerical studies of waves in the magnetotail (Fruit et al., 2002a,b; Louarn et al., 2004),

Correspondence to: M. Volwerk

(martin.volwerk@assoc.oeaw.ac.at) can now be tested with observations. This 3-D view has shown us the details of the so-called flapping motion of the current sheet (Sergeev et al., 2003, 2004; Zhang et al., 2002, 2005), kink mode oscillations (Volwerk et al., 2003a), and other processes that re-arrange the magnetic field in the magnetotail, like dipolarization (Nakamura et al., 2002) or reconnection (Runov et al., 2003; Volwerk et al., 2004; Oieroset et al., 2001). Also the structure of the current sheet (Runov et al., 2003, 2004, 2005) and of the plasma flows (Nakamura et al., 2002, 2004) has been studied.

With the launch of the Double Star (TC) spacecraft an extra "dimension" has been added to the investigation of the magnetotail. TC-1 has an equatorial orbit with an apogee of approximately $13 R_{E}$. This way, during conjunctions of Cluster and TC-1, one can obtain simultaneous data for points separated by $\sim 3-6 R_{E}$. In this way more information is obtained about, e.g., the propagation of dipolarization fronts (Nakamura et al., 2005) and the radial extension of the flapping motion (Zhang et al., 2005). Indeed, with this extra scale of $\sim 3-6 R_{E}$ the wave propagation and/or mode conversion in the tail can be studied and compared with theory and numerical models.

In this paper we discuss an event on 14 August 2004 when the Cluster spacecraft and TC-1 were located in the postmidnight region of the magnetotail, with their magnetic footpoints close together near the ground station Dikson (DIK) in Russia. Both TC-1 and Cluster enter the magnetotail plasma sheet during an earthward flow, albeit that TC-1 enters approximately $29 \mathrm{~min}$ earlier. Interestingly, both TC-1 and Cluster, although separated by $3 R_{E}$, observed similar ULF waves during this event. In the following sections, we will discuss the magnetometer data in detail in Sect. 2 and perform wave and timing analysis on the observed structures in Sect. 3. In the Sect. 4 we will come to an interpretation of the data presented in this paper. 

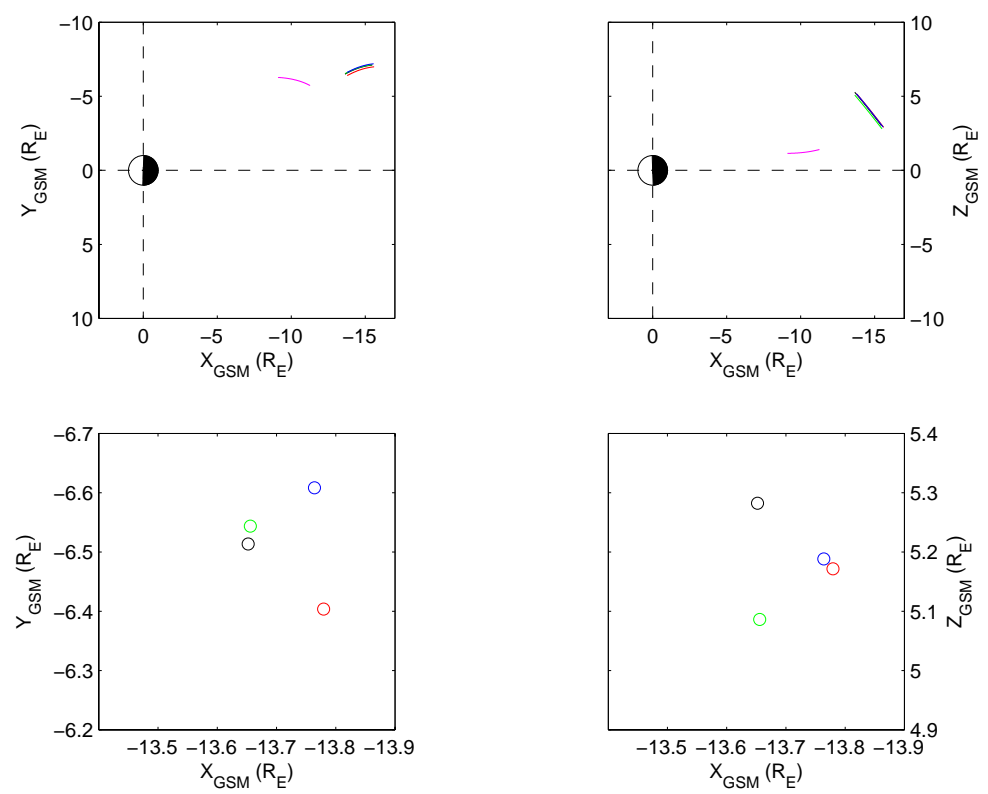

Fig. 1. Top panels: The location of Cluster (black, red, green and blue) and TC-1 (magenta) in GSM coordinates in the $x y$ - plane (left) and the $x z$-plane (right). Bottom panels: The relative locations of the 4 Cluster spacecraft in GSM coordinates with the usual colours in the $x y$ plane (left) and the $x z$-plane (right).

\section{Cluster and Double Star data}

Between 19:00 and 21:00 UT on 14 August 2004, the Cluster spacecraft were located in the northern lobe of the Earth's magnetotail. TC-1 was located in the southern lobe of the magnetotail. All spacecraft were at approximately the same $y_{\mathrm{GSM}} \approx-6 R_{E}$ with TC-1 at $x_{\mathrm{GSM}} \approx-11 R_{E}$ and Cluster at $x_{\mathrm{GSM}} \approx-14 R_{E}$. Note that although TC-1 is at $z_{\mathrm{GSM}} \approx 2 R_{E}$ and Cluster moves from $z_{\mathrm{GSM}} \approx 5.2$ to $z_{\mathrm{GSM}} \approx 3.0 R_{E}$ over the event, i.e. both at positive $z_{\mathrm{GSM}}$, they are situated in different hemispheres of the magnetotail. The location of the spacecraft is shown in Fig. 1. In the same figure the configuration of the Cluster spacecraft is shown in GSM coordinates.

We show the magnetic field data from Cluster (Balogh et al., 2001) and TC-1 (Carr et al., 2005) in Figs. 2 and 3. We show the low-pass filtered data (for periods $\tau \geq 1.5 \mathrm{~min}$ ) to clearly show the low frequency oscillation in the data. In the different panels, the Cluster spacecraft are labeled with their usual colours (black, red, green and blue), whereas the TC-1 data are plotted in a solid line, in magenta. The data show a magnetic structure passing by TC-1, starting at $\sim 19: 15$ UT, with the signature of a dipolarizing field or plasma sheet expansion region, i.e. a decrease in $B_{\mathrm{x}}$ combined with an increase in $B_{\mathrm{Z}}$. The spacecraft thus enters the plasma sheet and remains there. Similarly, the Cluster spacecraft see a magnetic structure with the signature of a dipolarization starting 20:00 UT. Note that for Cluster, this structure has a significant $B_{\mathrm{y}}$ component, which is often associated with the presence of field-aligned currents. This structure in Cluster is also reminiscent of the current sheet flapping structures discussed by Sergeev et al. (2003, 2004). Visual inspection shows that the data from TC- 1 and Cluster can be well aligned by shifting TC- 1 by $\sim 29 \mathrm{~min}$. To clarify the correspondence between the observations of TC-1 and Cluster we have added a gray line, representing the TC- 1 data shifted by $29 \mathrm{~min}$, and for $B_{\mathrm{x}}$ and $B_{\mathrm{y}}$ the sign has been reversed, in order to compensate for the different hemispheres where the spacecraft are located.

There is a surprisingly good match between the two data sets, both sets show the dipolarization-like structure over approximately the same time interval, and both show the low frequency oscillations of the magnetic field with a period of nearly 5 min (these will be discussed in Sect. 3). However, there are differences in the two data sets from Cluster and TC-1. First, in $B_{\mathrm{x}}$ one sees that for TC-1 this field component decreases from approximately $-18 \mathrm{nT}$ to $-8 \mathrm{nT}$, and does not return to its pre-event value, and thus the spacecraft remains in the plasma sheet. For Cluster one sees that the $x$-component of the magnetic field first returns again to almost pre-event values after $1 \mathrm{~h}$, i.e. Cluster enters the plasma sheet and then exits again. Then $B_{\mathrm{X}}$ decreases again, most likely as a result of Cluster nearing the neutral sheet and motion of the magnetotail. Another difference is that the dipolarization-like sturcture in Cluster is accompanied by a strong $B_{\mathrm{y}}$ signature $\left(\Delta B_{\mathrm{y}} \approx 10 \mathrm{nT}\right)$, whereas TC-1 has no significant $B_{\mathrm{y}}$ signature.

The magnetospheric activity level is very low, the AE index (not shown) only shows a slight increase over the interval observed, from $\sim 100$ to $\sim 250$. High latitude magnetometer stations may be better indicators for the magnetospheric activity seen by TC- 1 and Cluster. We show the data from ground stations near the footpoints of Cluster and TC-1 in Fig. 4. In the top panel we show the $B_{\mathrm{H}}$ components 

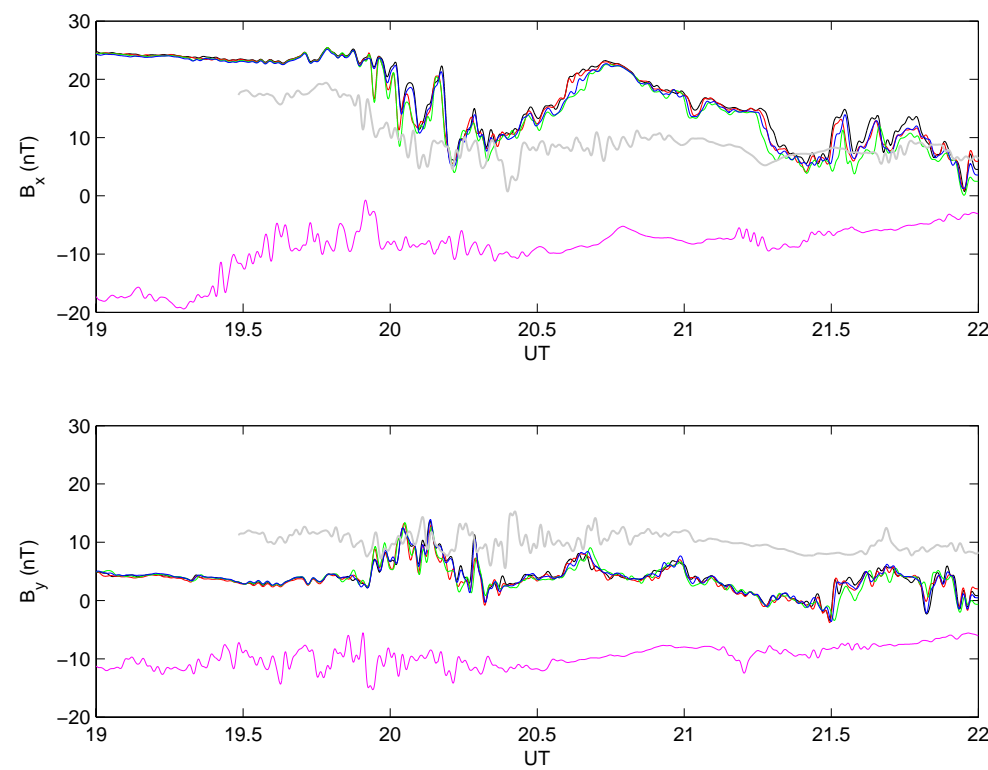

Fig. 2. The low-pass filtered ( $\tau \geq 1.5 \mathrm{~min}$ ) magnetic field data, $B_{\mathrm{x}}$ and $B_{\mathrm{y}}$, for Cluster (usual colours) and TC-1 (solid magenta line). The gray line shows the TC-1 data shifted by $29 \mathrm{~min}$ and sign-reversed to compensate for the opposite hemispheres.
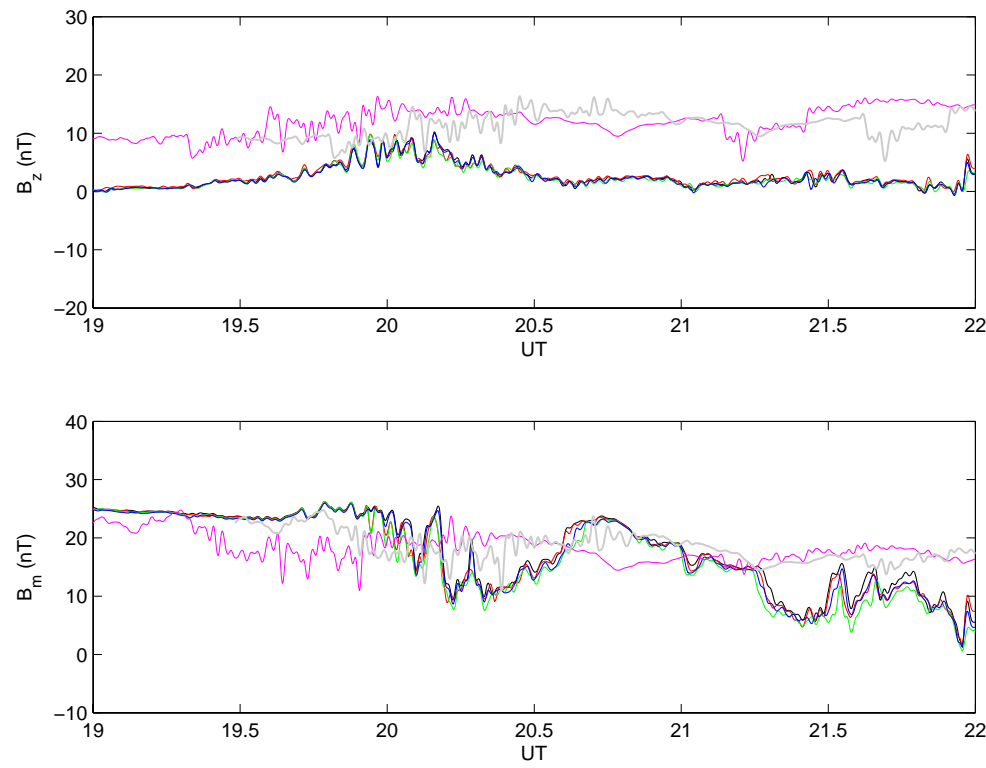

Fig. 3. The low-pass filtered ( $\tau \geq 1.5 \mathrm{~min}$ ) magnetic field data, $B_{\mathrm{Z}}$ and $B_{\mathrm{m}}$, for Cluster (usual colours) and TC-1 (solid magenta line). The gray line shows the TC- 1 data shifted by $29 \mathrm{~min}$.

of the Russian AARI (Arctic and Antarctic Research Institute) magnetometer station Dikson (DIK, CGM Lat. 68.3 ${ }^{\circ}$ and CGM Lon. $155.9^{\circ}$, red line) and Cape Chelyuskin (CCS, CGM Lat. $71.6^{\circ}$ and CGM Lon. $175.3^{\circ}$, black line), and in the bottom panel the $B_{\mathrm{Z}}$ components. It is clear that there is a strong current system between these two stations, with DIK showing a negative and CCS showing a strong positive bay.

During the event at $\sim 20: 00$ UT, the CIS instrument on board Cluster (Rème et al., 2001) shows a strong earthward flow, $v_{\mathrm{x}} \approx 600 \mathrm{~km} / \mathrm{s}$ (data not shown in this paper). In the TC-1 CIS data (Rème et al., 2005) we find that for the event at $\sim 19: 30$ UT there is a less strong earthward flow, $v_{\mathrm{x}} \approx 300 \mathrm{~km} / \mathrm{s}$ (data not shown in this paper, summary plots available at the DSDSweb http://edds02.iwf.oeaw.ac.at/ dsdsweb/). This flow is maintained until after 20:00 UT.

\section{Wave analysis}

From a visual inspection one can see that the oscillations in $B_{\mathrm{X}}$, observed between 19:30 and 20:00 UT by TC-1, agree 

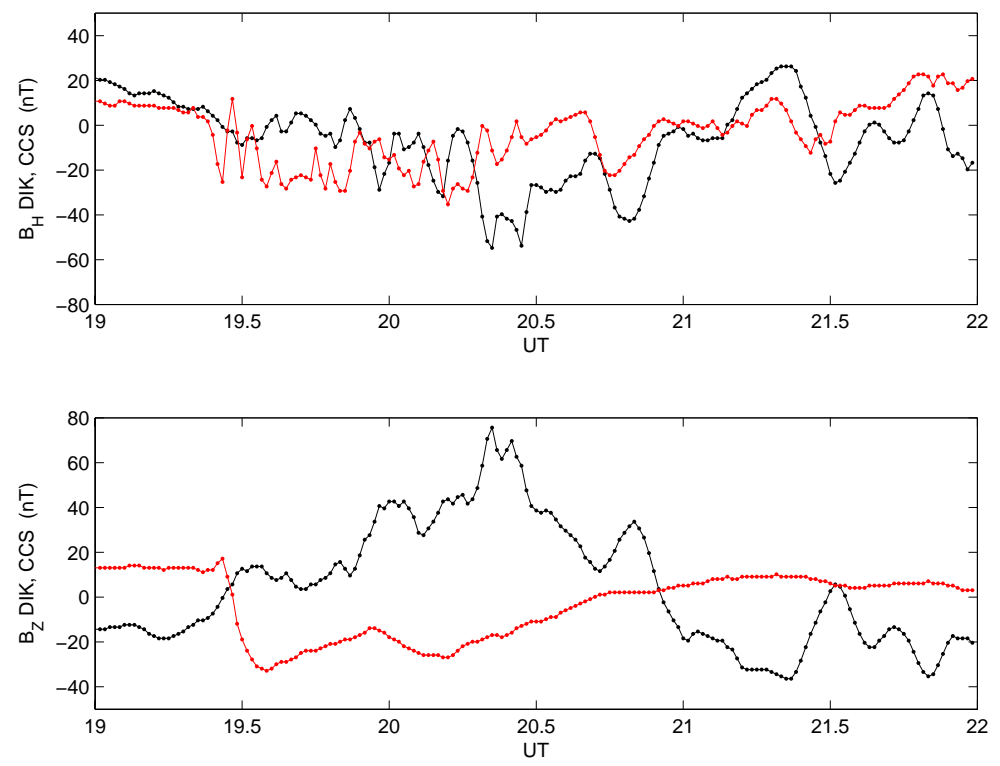

Fig. 4. The $B_{\mathrm{H}}$ and $B_{\mathrm{Z}}$ components measured by DIK (red) and CCS (black) of the AARI magnetometers. A negative bay in $B_{\mathrm{H}}$, with large oscillations, starts almost simultaneously with the dipolarization observed by TC-1, which has its magnetic footpoint near DIK; CCS shows no such oscillations. The $B_{\mathrm{Z}}$ component shows a negative bay in DIK, however, a strong positive bay in CCS.

very well with those seen by Cluster 29 min later, albeit not in amplitude. We investigate the waves using spectral analysis of the non-filtered data, and use a timing method (Harvey, 1998) on the Cluster data to obtain the propagation direction of the waves.

\subsection{Spectral analysis}

We perform spectral analysis on the mean field-aligned (MFA) magnetic field data from Cluster (sampled at $2 \mathrm{~Hz}$ ) and from TC-1 (sampled every $4 \mathrm{~s}$ ). The mean magnetic field is obtained by a low-pass Butterworth filter and the data are transformed into compressional, left-handed and righthanded polarized components. The spectra are averaged over 7 harmonics. The analysis of the data sets shows that indeed the same oscillations appear in the data sets (see Fig. 5). There is a broad peak in the Cluster compressional spectrum at $f \approx 2 \mathrm{mHz}$, corresponding to periods of $500 \mathrm{~s}$ or $8.3 \mathrm{~min}$. More interesting, however, are the already mentioned low frequency waves near the 5-min period. The vertical dashed lines in Fig. 5 shows the location of the 5-min waves, i.e. $f \approx 3.3 \mathrm{mHz}$. In the Cluster spectra these waves show up in both the left- and right-handed components at equal power, indicating that the waves are linearly polarized. In the TC-1 spectra, however, we find that these waves are present in the compressional component.

Almost simultaneously, with the large oscillations seen in TC-1, starting at $\sim 19: 30$ UT, there are large oscillations in the $B_{\mathrm{H}}$ component of the ground station DIK. Although the sampling rate is rather low $(1 \mathrm{~min})$, the peaks are well defined by 5 data points per peak, indicating a period of around 5 min. Indeed, in the DIK spectra the waves observed by
TC-1 are also present in both the $\mathrm{H}$ and $\mathrm{E}$ components, i.e. in an elliptical polarization.

This means that we may be seeing a large-scale oscillation in the Pc5 range $(2-7 \mathrm{mHz})$. However, these waves are first present when the magnetic structure is near the spacecraft, and the earthward flow is present. This might indicate that the flow is driving these oscillations (see, e.g. Baumjohann and Glassmeier, 1984, for a similar event involving Pi2 waves). We will discuss this further in Sect. 4.

\subsection{Timing analysis}

We use a timing method on the Cluster data (see, e.g. Harvey, 1998; Volwerk et al., 2003a), where we make a crosscorrelation of the $x$-component of the magnetic field data to obtain the lag times between the spacecraft. We have timed the Cluster data for the ULF waves in the interval 20:0620:18 UT, when the Cluster spacecraft enter the plasma sheet and observe the fast earthward flow $\left(v_{\mathrm{x}} \approx 600 \mathrm{~km} / \mathrm{s}\right)$. For the ULF waves seen in $B_{\mathrm{x}}$ we find the following propagation velocity: $\mathbf{v}=(-84,194,-4) \mathrm{km} / \mathrm{s}$. This means that the waves are moving mainly towards midnight, and tailward. This is the wave velocity in the Cluster rest frame; to obtain the wave velocity in the plasma rest frame, we will have to add the plasma flow velocity, which would result in the waves travelling tailward with a velocity $v_{\mathrm{x} \text {, wave }} \approx 684 \mathrm{~km} / \mathrm{s}$. Assuming a density of $\sim 0.1 \mathrm{~cm}^{-3}$ and a magnetic field strength of $\sim 10 \mathrm{nT}$ we obtain an Alfvén velocity of $v_{\mathrm{A}} \approx 700 \mathrm{~km} / \mathrm{s}$, which means that these linearly polarized waves are travelling with the Alfvén velocity.

To obtain the velocity of the low frequency magnetic structure (the spacecraft moving from the lobes into the plasma sheet), we perform a timing analysis on low-pass filtered data 
between 19:54 and 20:06 UT, determining the passage of $B_{\mathrm{x}}=B_{0}$ for $15 \leq B_{0} \leq 22 \mathrm{nT}$ in steps of $1 \mathrm{nT}$. The determination of the velocity is very stable, giving a mean value of $\mathbf{v} \approx(0.8,-6.6,-0.2) \mathrm{km} / \mathrm{s}$. This is a much smaller velocity (by an order of magnitude) than similar events found by Sergeev et al. (2004), which were determined to be magnetotail flapping. Interestingly, we find that the structure itself is moving away from midnight, as also shown by Sergeev et al. (2004) for flapping motions, whereas the low frequency waves are moving towards midnight.

In comparison, we can determine the velocity of the structure moving from TC-1 located at $(-11.8,-5.4,1.5) R_{E}$ to Cluster located at $(-12.9,-6.1,6.8) R_{E}$, under the assumption that the dipolar field region, or the plasma sheet expansion, is moving from TC-1 to Cluster. The signal is observed at Cluster 29 min later than at TC-1, which means it would travel in the $x y$-plane with a velocity of $\mathbf{v}_{\mathrm{xy}} \approx(-4,-2.6) \mathrm{km} / \mathrm{s}$; the structure moves down the tail, expanding the low magnetic field region in the centre of the tail. Apparently, either there are spatial variations in the large structure which cause the timing analysis on the Cluster data show a slow positive $v_{\mathrm{x}}$, or our assumption that the structure is moving from TC-1 to Cluster is wrong. We will discuss this in Sect. 4. Nakamura et al. (2002) found that a $2000-\mathrm{km}$ thick dipolarization front moved over Cluster in an earthward-dawnward direction with a velocity of $77 \mathrm{~km} / \mathrm{s}$; these kind of structures move much faster than what is observed in this paper. The plasma flow was directed almost parallel to the dipolarization front. Apart from the absolute velocity, the event in this paper shows similarities in the propagation direction of the dipolarization front with the Nakamura et al. (2002) event.

\section{Discussion}

We have studied the magnetic structure observed both by TC1 and Cluster, under the assumption that this structure was a dipolarized field region moving past the spacecraft. It consists of a decrease in the $x$-component of the magnetic field, combined with an increase in the $z$-component and an earthward plasma flow. In the Cluster data there is also a considerable $y$-component to the structure moving past the spacecraft. It may be due to a temporal/localized expanded plasma sheet structure.

The flapping motion of the current sheet, as discussed by Sergeev et al. (2004) and Zhang et al. (2005), which tends to move mainly in the $y$-direction, could be related to the structure observed by TC- 1 and Cluster. Minimum variance analysis of the structure passing by TC-1 shows that the direction with minimum eigen value is $(0.1,0.6,-0.8)$. This indicates a motion in the $y z$-direction. Therefore, the structure observed is more like a flapping of the current sheet, although the average plasma flow for these cases is much smaller than observed in this paper, and the propagation velocity of the structure in this paper is almost an order of magnitude smaller than in Sergeev et al. (2004).
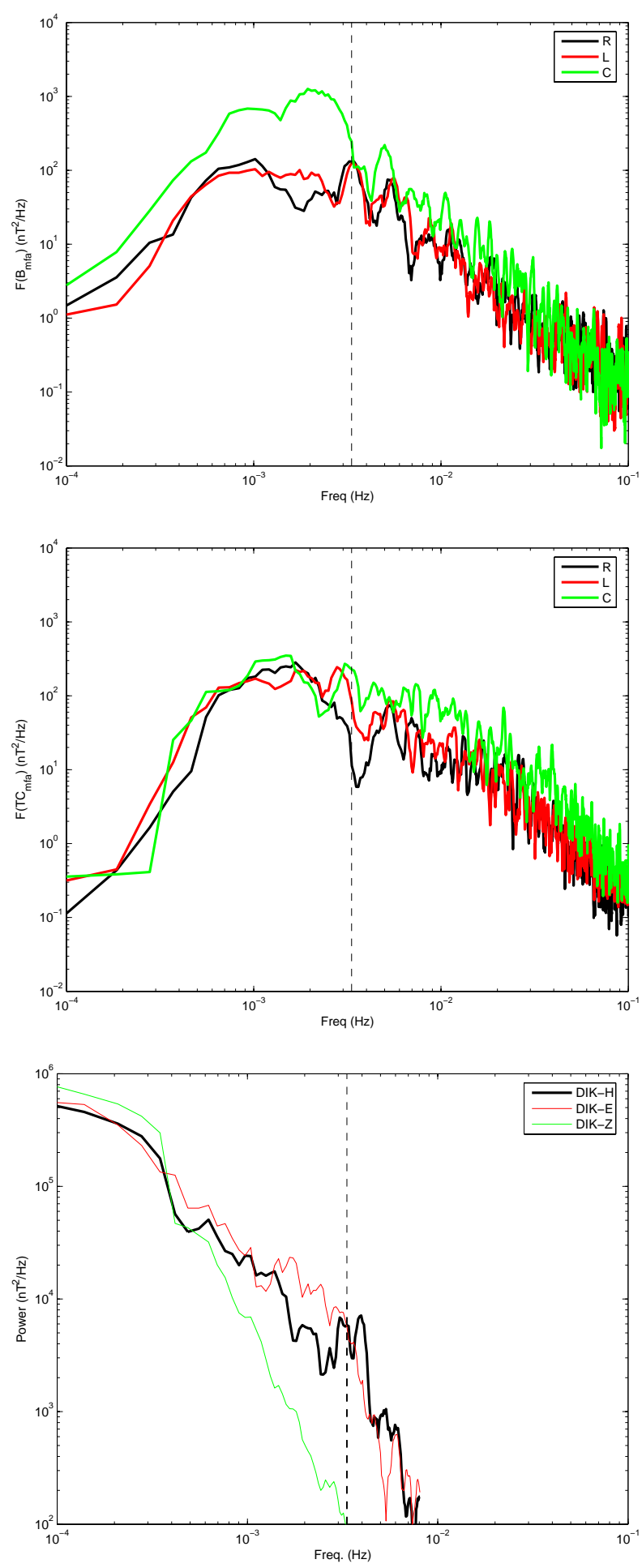

Fig. 5. Power spectra for Cluster, TC-1 and DIK for the interval 19:00-21:00 UT. For C1 and TC-1 the spectra are shown in a MFA coordinate system with compressional, left- and right-handed polarized waves. The DIK spectra are from the $\mathrm{H}, \mathrm{E}$ and $\mathrm{Z}$ components of the ground magnetic field. Note that the $y$-axis for DIK is different from the other two. The vertical dashed line indicates the location for 5-min waves at $f \approx 3.3 \mathrm{mHz}$. 


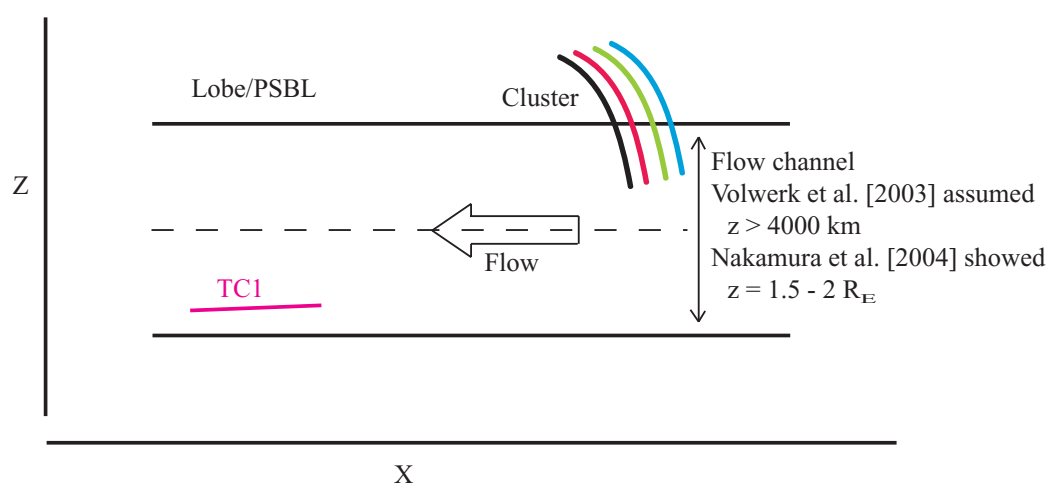

Fig. 6. Schematic view of the spacecraft entering the plasma sheet flow channel. TC-1, remaining on near constant $z_{\text {GSM }}$ observes the creation of the flow channel and remains in this channel. The low velocity flow is maintained until after 20:00 UT. Twenty-nine min later, Cluster has moved in $z_{\mathrm{GSM}}$ and enters the flow channel, observing that the magnetic field "dipolarizes" and the plasma flow.

There is, however, an alternative interpretation of the observed structure, which avoids the mismatch in velocities. Nakamura et al. (2004) has shown that the plasma flow channel in the magnetotail is of limited size, i.e. $\sim 3 R_{E}$ in the $y$-direction and $\sim 2 R_{E}$ in the $z$-direction. Indeed, the vertical separation between TC- 1 and Cluster is at "onset TC$1 " \sim 3 R_{E}$. TC-1 observes earthward flow at $\sim 300 \mathrm{~km} / \mathrm{s}$ and thereby the creation of a flow channel, whereas Cluster observes an unperturbed lobe field. After 29 min, when TC-1 still observes the low velocity plasma flow, the Cluster spacecraft have moved approximately $0.4 R_{E}$ in $z_{\mathrm{GSM}}$. This will move Cluster to the boundary of the flow channel already observed by TC- 1 . Here we have to assume that TC-1, which basically does not move in $z$, was located inside the flow channel region already before the flow started. Thus, the structure observed by Cluster is the entry of the spacecraft into the flow channel, which also explains the slow motion of, what we called before, the "local dipolarization" or "flapping." The flow perturbs the magnetic field, bending it from $B_{\mathrm{x}}$ into $B_{\mathrm{Z}}$. The difference in flow velocity between TC- 1 and Cluster, $\sim 300$ and $\sim 600 \mathrm{~km} / \mathrm{s}$, respectively, is then explained by flow braking, where the assumption is made that the plasma flow channel can exist for as long as half an hour, which is shown from the TC-1 CIS data to be the case. The flow velocities measured are, in general, in good agreement with those measured in flow channels by, for example, Volwerk et al. (2003b) and Nakamura et al. (2004). A schematic view of this process is shown in Fig. 6.

The ULF waves in the PC5 range, observed by both TC1 and Cluster, are mainly present during the passage of the magnetic structure, during the earthward plasma flow. As the ULF waves are mainly located around the front, which we now can assume is the boundary of the flow channel, one can imagine that they are created by a streaming instability on that boundary (see, e.g. Holter et al., 1995; Volwerk et al., 2003b). The waves may be eigen modes of the flow channel. The propagation direction measured by Cluster is tailward, with a velocity near the local Alfvén velocity, and the waves are linearly polarized. In contrast, the waves are also observed by the ground stations, possibly indicating a central source of the waves. Also, TC-1 shows the waves as compressional, which means that between TC- 1 and Cluster there has to be a mode conversion. Similarly, these waves have an elliptical polarization on the ground. DIK shows a peak in the spectra of both the $\mathrm{H}$ and $\mathrm{E}$ components. Further investigation of the wave characteristics, mode conversion and generation for this event is underway.

Acknowledgements. The authors would like to thank O. Troshichev for providing the AARI magnetometer data. We thank the DSDSweb for making the TC summary plots available. The work by M. Volwerk and K.-H. Glassmeier was financially supported by the German Bundesministerium für Bildung und Forschung and the Zentrum für Luft- und Raumfahrt under contracts 50 OC 0104 and 50 OC 0105, respectively.

Topical Editor T. Pulkkinen thanks two referees for their help in evaluating this paper.

\section{References}

Angelopoulos, V., Baumjohann, W., Kennel, C. F., Coroniti, R. V., Kivelson, M. G., Pellat, R., Walker, R. J., Lühr, H., and Paschman, G.: Bursty bulk flows in the inner central plasma sheet, J. Geophys. Res., 97, 4027-4039, 1992.

Angelopoulos, V., Kennel, C. F., Coroniti, F. V., Pellat, R., Kivelson, M. G., Walker, R. J., Russell, C. T., Baumjohann, W., Feldman, W. C., and Gosling, J. T.: Statistical characteristics of bursty bulk flow events, J. Geophys. Res., 99, 21 257-21 280, 1994.

Balogh, A., Carr, C. M., Acuña, M. H., Dunlop, M. W., Beek, T. J., Brown, P., Fornacon, K.-H., Georgescu, E., Glassmeier, K.-H., Harris, J., Musmann, G., Oddy, T., and Schwingenschuh, K.: The Cluster magnetic field investigation: Overview of inflight perfomance and initial results, Ann. Geophys., 19, 1207-1217, 2001, SRef-ID: 1432-0576/ag/2001-19-1207.

Bauer, T. M., Baumjohann, W., and Treumann, R. A.: Neutral sheet oscillations at substorm onset, J. Geophys. Res., 100, $23737-$ 23 743, 1995a.

Bauer, T. M., Baumjohann, W., Treumann, R. A., Sckopke, N., and Lühr, H.: Low-frequency waves in the near-Earth plasma sheet, J. Geophys. Res., 100, 9605-9617, 1995b. 
Baumjohann, W. and Glassmeier, K.-H.: The transient response mechanism and pi2 pulsations at substorm onset-review and outlook, Planet. Space Sci., 11, 1361-1370, 1984.

Carr, C., Brown, P., Zhang, T. L., Gloag, J., Horbury, T., Lucek, E., Magnes, W., O’Brien, H., Oddy, T., Auster, U., Austin, P., Aydogar, O., Balogh, A., Baumjohann, W., Beck, T., Eichelberger, H., Fornaçon, K.-H., Georgescu, E., Glassmeier, K.-H., Ludlam, M., Nakamura, R., and Richter, I.: The Double Star magnetic field investigation: instrument design, performance and highlights of the first year's observation, Ann. Geophys., 23, 27132732, 2005.

Chen, S.-H. and Kivelson, M. G.: On ultralow frequency waves in the lobes of the Earth's magnetotail, J. Geophys. Res., 96, 15 711-15 723, 1991.

Fruit, G., Louarn, P., Tur, A., and Quéau, D. L.: On the propagation of magnetohydrodynamic perturbations in a harristype current sheet: 1. propagation on discrete modes and signal reconstruction, J. Geophys. Res., 107(A11), 1411, doi:10.1029/2001JA009212, 2002a.

Fruit, G., Louarn, P., Tur, A., and Quéau, D. L.: On the propagation of magnetohydrodynamic perturbations in a Harristype current sheet: 2. propagation on continuous modes and resonant absorption, J. Geophys. Res., 107(A11), 1412, doi:10.1029/2001JA009215, 2002b.

Harvey, C. C., Spatial gradients and volumetric tensor, in Analysis Methods for Multi-Spacecraft Data, edited by: Paschmann, G. and Daly, P., 307-322, ESA, Noordwijk, 1998.

Holter, Ø., Altman, C., Roux, A., Perraut, S., Pedersen, A., Pécseli, H., Lybekk, B., Trulsen, J., Korth, A., and Kremser, G.: Characterization of low frequency oscillations at substorm breakup, J. Geophys. Res., 100, 19 109-19 119, 1995.

Louarn, P., Fruit, G., Budnik, E., Sauvaud, J.-A., Jacquey, C., Quéau, D. L., Rème, H., Lucek, E., Balogh, A., et al.: On the propagation of low frequency fluctuations in the plasmasheet: 1. CLUSTER observations and magnetohydrodynamic analysis, J. Geophys. Res., 109, A03 216, doi:10.1029/2003JA010228, 2004.

Nakamura, R., Baumjohann, W., Klecker, B., Bogdanova, Y., Balogh, A., Rème, H., Bosqued, J. M., Dandouras, I., Sauvaud, J.-A., Glassmeier, K.-H., Kistler, L., Mouikis, C., Zhang, T. L., Eichelberger, H., and Runov, A.: Motion of the dipolarization front during a flow burst event observed by Cluster, Geophys. Res. Lett., 29, 1942, doi:10.1029/2002GL015763, 2002.

Nakamura, R., Baumjohann, W., Mouikis, C., Kistler, L. M., Runov, A., Volwerk, M., Asano, Y., Vörös, Z., Zhang, T. L., Klecker, B., Rème, H., and Balogh, A.: Spatial scale of high-speed flows in the plasma sheet observed by Cluster, Geophys. Res. Lett., 31, L09 894, doi:10.1029/2004GL019558, 2004.

Nakamura, R., Baumjohann, W., Zhang, T. L., Carr, C. M., Balogh, A., Fornaçon, K.-H., Georgescu, E., Rème, Dandouras, H. I., Takada, T., Volwerk, M., Asano, Y., Runov, A., Eichelberger, H., Klecker, B., Mouikis, C., Kistler, L. M., and Amm, O.: Cluster and Double Star observations of dipolarization, Ann. Geophys., 23, 2915-2920, 2005.

Oieroset, M., Phan, T. D., Fujimoto, M., Lin, R. P., and Lepping, R. P.: In situ detection of collisionless reconnection in the Earth's magnetotail, Nature, 412, 414-417, 2001.

Rème, H., Aostin, C., Bosqued, J. M., Danduras, I., Lavraud, B., Sauvaud, J.-A., Barthe, A., Bouyssou, J., Camus, T., Coeur-Joly, O., et al.: First multispacecraft ion measurements in and near the Earth's magnetosphere with the identical Cluster ion spectrometry (CIS) experiment, Ann. Geophys., 19, 1303-1354, 2001,

\section{SRef-ID: 1432-0576/ag/2001-19-1303.}

Rème, H., Dandouras, I., Aoustin, C., Bosqued, J. M., Sauvaud, J. A., Cao, J. B., Shi, J., Pu, Z., Bavassano-Cattaneo, M. B., Parks, G. K., Carlson, C. W., Klecker, B., Moebius, E., Kistler, L., Korth, A., Lundin, R., Escoubet P., and the HIA team: The HIA instrument on the Tan Ce 1 Double Star near-equatorial spacecraft and its first results, Ann. Geophys., 23, 2757-2774, 2005.

Runov, A., Nakamura, R., Baumjohann, W., Treumann, R. A., Zhang, T. L., Volwerk, M., Vörös, Z., Balogh, A., Glassmeier, K.-H., Klecker, B., Rème, H., and Kistler, L.: Current sheet structure near magnetic X-line observed by Cluster, Geophys. Res. Lett., 30, 1579, doi:10.1029/2002GL016730, 2003.

Runov, A., Sergeev, V., Nakamura, R., Baumjohann, W., Vörös, Z., Volwerk, M., Asano, A., Klecker, B., Rème, H., and Balogh, A.: Properties of a bifurcated current sheet observed on 29 August 2001, Ann. Geophys., 22, 2535-2540, 2004,

\section{SRef-ID: 1432-0576/ag/2004-22-2535.}

Runov, A., Sergeev, V. A., Nakamura, R., Baumjohann, W., Zhang, T. L., Asano, Y., Volwerk, M., Vörös, Z., Balogh, A., and Rème, H.: Reconstruction of the magnetotail current sheet structure using multi-point Cluster measurements, Planet. Space Sci., 53, 237-243, 2005.

Sergeev, V., Runov, A., Baumjohann, W., Nakamura, R., Zhang, T. L., Volwerk, M., Balogh, A., Rème, H., Sauvaud, J.-A., André, M., and Klecker, B.: Current sheet flapping motion and structure observed by Cluster, Geophys. Res. Lett., 30, 1327, doi:10.1029/2002GL016500, 2003.

Sergeev, V., Runov, A., Baumjohann, W., Nakamura, R., Zhang, T. L., Balogh, A., Louarn, P., Sauvaud, J.-A., and Rème, H.: Orientation and propagation of current sheet oscillations, Geophys. Res. Lett., 31, L05 807, doi:10.1029/2003GL019346, 2004.

Volwerk, M., Glassmeier, K.-H., Runov, A., Baumjohann, W., Nakamura, R., Zhang, T. L., Klecker, B., Balogh, A., and Rème, H.: Kink mode oscillation of the current sheet, Geophys. Res. Lett., 30, 1320, doi:10.1029/2002GL016467, 2003a.

Volwerk, M., Nakamura, R., Baumjohann, W., Treumann, R. A., Runov, A., Vörös, Z., Zhang, T. L., Asano, Y., Klecker, B., Richter, I., Balogh, A., and Rème, H.: A statistical study of compressional waves in the tail current sheet, J. Geophys. Res., 108, 1429, doi:10.1029/2003JA010155, 2003 b.

Volwerk, M., Glassmeier, K.-H., Runov, A., Nakamura, R., Baumjohann, W., Klecker, B., Richter, I., Balogh, A., Rème, H., and Yumoto, K.: Flow burst induced large scale plasma sheet oscillation, J. Geophys. Res., 109, A11208, doi:10.1029/2004JA010533, 2004.

Zhang, T. L., Baumjohann, W., Nakamura, R., Balogh, A., and Glassmeier, K.-H.: A wavy twisted neutral sheet observed by Cluster, Geophys. Res. Lett., 29, 1899, doi:10.1029/2002GL015544, 2002.

Zhang, T. L., Baumjohann, W., Nakamura, R., Volwerk, M., Runov, A., Vörös, Z., Glassmeier, K.-H., and Balogh, A.: Neutral sheet normal direction determination, Adv. Space Res., 99, in press, 2005.

Zhang, T. L., Nakamura, R., Volwerk, M., Runov, A., Baumjohann, W., Eichelberger, H. U., Carr, C., Balogh, A., Sergeev, V., Shi, J. K., and Fornaçon, K.-H.: Double Star/Cluster observations of neutral sheet oscillations on 5 August 2004, Ann. Geophys., 23, 2909-2914, 2005.

Zhou, X.-Y., Russell, C. T., Gosling, J. T., and Mitchell, D. G.: Three spacecraft observations of the geomagnetic tail during moderately disturbed conditions: Structure and evolution of the current sheet, J. Geophys. Res., 102, 14 415-14 424, 1997. 